\title{
Análise estratigráfica e distribuição do arsênio em depósitos sedimentares quaternários da porção sudeste do Quadrilátero Ferrífero, bacia do Ribeirão do Carmo, MG
}

\author{
Stratigraphic analysis and distribution of arsenic in quaternary \\ sedimentary deposits of the southeastern portion of the Quadrilátero \\ Ferrífero, basin of the Ribeirão Carmo, MG
}

Adivane Terezinha Costa

Doutora em Ciências Naturais DEGEO/UFOP

E-mail: adivane@degeo.ufop.br

Hermínio Arias Nalini Jr

Doutor em Geologia Mineira DEGEO/UFOP

E-mail: nalini@degeo.ufop.br

Paulo de Tarso Amorim Castro

Doutor em Geologia DEGEO/UFOP

E-mail: ptacastro@gmail.com

Sonia Hatsue Tatumi

Doutora em Ciência - FATEC

E-mail: labvidro@fatecsp.br

\section{Resumo}

A região do $\mathrm{QF}$, em Minas Gerais, tornou-se internacionalmente conhecida pela exploração de ouro no século XVIII. Nesse artigo, serão apresentados valores de referência (background) para o arsênio em sedimentos aluviais provenientes de áreas que foram intensamente afetadas pela exploração de ouro no passado, contidas na bacia do ribeirão do Carmo. A análise da sucessão faciológica dos perfis aluviais foi realizada em depósitos sedimentares de planícies de inundação, barrancos de rios (cutbank) e terraços aluviais e foi o alicerce para a obtenção do valor de referência do arsênio em depósitos de fácies de canal e de planícies de inundação. A partir do conhecimento do valor de referência obtido pelo método estatístico, com base na confecção de curvas de freqüência acumulada em escala linear, foram gerados mapas geoquímicos no sistema SIG. A obtenção do valor de referência e do mapa geoquímico do arsênio, na bacia do ribeirão do Carmo, com representação das áreas com concentrações anômalas desse elemento, é fundamental para o diagnóstico e planejamento ambiental de um distrito mineiro potencialmente contaminado por arsênio.

Palavras-chave: Valor de referência, arsênio, sedimentos, planícies de inundação, terraços aluviais, Quadrilátero Ferrífero.

\begin{abstract}
The Quadrilátero Ferrífero region, in the State of Minas Gerais, became internationally known due to the exploitation of gold in the eighteenth century. In this paper, we will present background values for arsenic in alluvial sediments from areas that were heavily affected by the exploitation of gold in the past, in the Carmo River Basin. The analyses of the facies succession of the alluvial profiles were carried out in the sedimentary deposits of flood plains, cutbank and alluvial terraces; this being the foundation for obtaining the arsenic background in the facies of the channel and flood plains. From the knowledge of the background obtained by the statistical method, and based on the construction of cumulative frequency curves on a linear scale, geochemical maps were generated in the SIG system. The acquisition of the background values and the geochemical map for arsenic in the Carmo River Basin, representing areas with anomalous concentrations of this element, are essential for the diagnosis and environmental planning of a mining district potentially contaminated by arsenic.
\end{abstract}

Keywords: Background, arsenic, sediments, flood plains, alluvial terraces, Quadrilátero Ferrífero. 
Análise estratigráfica e distribuição do arsênio em depósitos sedimentares quaternários da ...

\section{Introdução}

Desde o final do século XVII, o Quadrilátero Ferrífero tem se destacado como uma das mais famosas regiões produtoras de ouro do Brasil. A descoberta do ouro, na região de Ouro Preto, ocorreu em 1698, cujas extrações ocorriam essencialmente nos leitos dos rios. Instalaram-se, a partir desse período, técnicas rudimentares de extração por garimpo em aluviões e, posteriormente, em minas. Padrões modernos de exploração surgiram em 1817 com a criação da primeira empresa de mineração de ouro: Mina de Passagem (Eschwege, 1979).

O sistema aluvial do ribeirão do Carmo é uma potente área de contaminação antiga e recente, pois os rejeitos dos garimpos e das antigas minas de ouro de Mariana e Ouro Preto eram lançados diretamente nesse rio. Vale ressaltar que o rio Gualaxo do Norte, afluente da margem esquerda do ribeirão do Carmo, também apresenta influência das antigas explorações auríferas, posicionadas no flanco norte do Anticlinal de Mariana, região de Antônio Pereira.

Nas mineralizações auríferas mesotermais hospedadas em greestone belts do Quadrilátero Ferrífero, participaram fluidos que transportaram, além do ouro, elementos como $\mathrm{As}, \mathrm{Sb}, \mathrm{Cu}, \mathrm{Pb}$ e $\mathrm{Zn}$ (Borba, 2002). Em sedimentos do ribeirão do Carmo e rio Gualaxo do Norte, os metais $\mathrm{Hg}, \mathrm{As}, \mathrm{Pb}, \mathrm{Zn}, \mathrm{Cu}, \mathrm{Cd}, \mathrm{Co}$, Cr e Ni são componentes da degradação da atividade extrativo-mineral, inclusive das atividades já exauridas. Desses metais, o As se apresenta como o maior problema ambiental, não só pela elevada toxidade, mas também pelas concentrações alarmantes que se encontram em águas e sedimentos dos rios da região (Eleutério, 1997, Costa, 2006).

Os depósitos auríferos da Mina de Passagem ocorrem no contato entre rochas do grupo Nova Lima e do Supergrupo Minas (Figura 1), associados a grandes quantidades de arsenopirita, em veios de quartzo e carbonatados ou disseminados em formação ferrífera, turmalinito, filito e quartzito (Vial, 1988).
Oficialmente, 35 toneladas de ouro foram extraídas da Mina de Passagem, durante 284 anos de exploração. Considerando a relação mínima ouro/arsênio sendo equivalente a 1/300 (Borba, 2002), estima-se que aproximadamente 10500 toneladas de As foram disponibilizados para águas e sedimentos da bacia do ribeirão do Carmo (Costa, 2007).

A liberação do arsênio para as vias hídricas depende do tipo e resistência do mineral, da mobilidade das espécies químicas e das condições físico-químicas do meio (Eleutério, 1997, Borba, 2002). A via mais comum de exposição humana ao arsênio é o consumo de água contaminada, porém a inalação de gases (arsina) e a ingestão de pó proveniente de solos contaminados podem ter importância local (WHO, 2001).

A Organização Mundial de Saúde (WHO, 2001), com base em evidências toxicológicas associadas à exposição ao As, como os grandes desastres ocorridos em Bangladesh, West Bengal, Tailândia, entre outros, foi motivada a abaixar o limite da concentração permitida de As em águas potáveis de $0,05 \mathrm{mg} / \mathrm{L}$ para 0,01 mg/L. No ano de 2003, o Brasil, através da resolução do CONAMA 357 , de março de 2005, também diminuiu o limite da concentração de As em águas potáveis (classe 1 a 3) para $0,01 \mathrm{mg} / \mathrm{L}$.

Estudos ambientais no Brasil, associados às fontes antropogênicas de contaminação de águas e sedimentos por As, estão em sua maioria relacionados com atividades de mineração aurífera como no Vale do Ribeira (SP) por Figueiredo et al. (2000) e no Quadrilátero Ferrífero por Oliveira et. al (1999), Eleutério (1997), Ladeira (1999), Matschullat et al. (2000), Costa (2001), Pimentel (2001), Borba (2002), Pereira (2006) e Costa (2007).

Em águas coletadas em algumas minas auríferas e nascentes de Ouro Preto e Mariana (Borba, 2002), pertencentes à bacia do Ribeirão do Carmo, foram encontradas concentrações de As total variando de 2 a $2980 \mu \mathrm{g} / \mathrm{L}$ e de $\mathrm{As}^{3+}$ de 1 a $86 \mu \mathrm{g} / \mathrm{L}$. As fontes geogênicas de As estão relacionadas às rochas que hospedam os depósitos auríferos sulfetados (Borba, 2002), sendo que as fontes antropogênicas diretas e indiretas de As são as pilhas de rejeitos, solos e sedimentos contaminados pela exploração aurífera histórica.

Nesse contexto, o objetivo do presente artigo é apresentar os resultados da investigação e quantificar as concentrações de arsênio em depósitos sedimentares de planícies de inundação e terraços aluviais existentes no Ribeirão do Carmo e compreender o controle do ambiente deposicional na acumulação de arsênio, através do estudo de fácies estratigráficas. Tais ambientes são considerados importantes locais de acumulação de metais e, devido a sua estreita interação com águas superficiais e subterrâneas, representam importantes fontes secundárias desse elemento para vias hídricas. Vale ressaltar que, em sedimentos fluviais, a assinatura geoquímica é diferenciada para sedimentos finos depositados em planícies de inundação e sedimentos de granulometria grossa depositados em canal.

A indicação de áreas-fonte, a sugestão de valores de referência (background) e o uso de cartografia para delimitação de áreas de risco geoquímico natural ou de contaminação antropogênica de arsênio em sedimentos do ribeirão do Carmo e do rio Gualaxo do Norte também são contemplados nesse trabalho.

Assim, valores de referência locais são sugeridos na tentativa de distinguir entre a composição geoquímica natural ou geogênica dos sedimentos depositados na bacia do ribeirão do Carmo, antes da implantação da exploração aurífera no final do século XVII, e a composição geoquímica originada por contribuição antrópica, ou seja, influenciada pela exploração mineral histórica.

\section{Materiais e métodos}

A amostragem vertical de sedimentos das planícies de inundação e de terraços aluviais foi realizada basicamente de quatro formas (Figura 2): coletas de dois testemunhos verticais realizados 
Adivane Terezinha Costa et al.

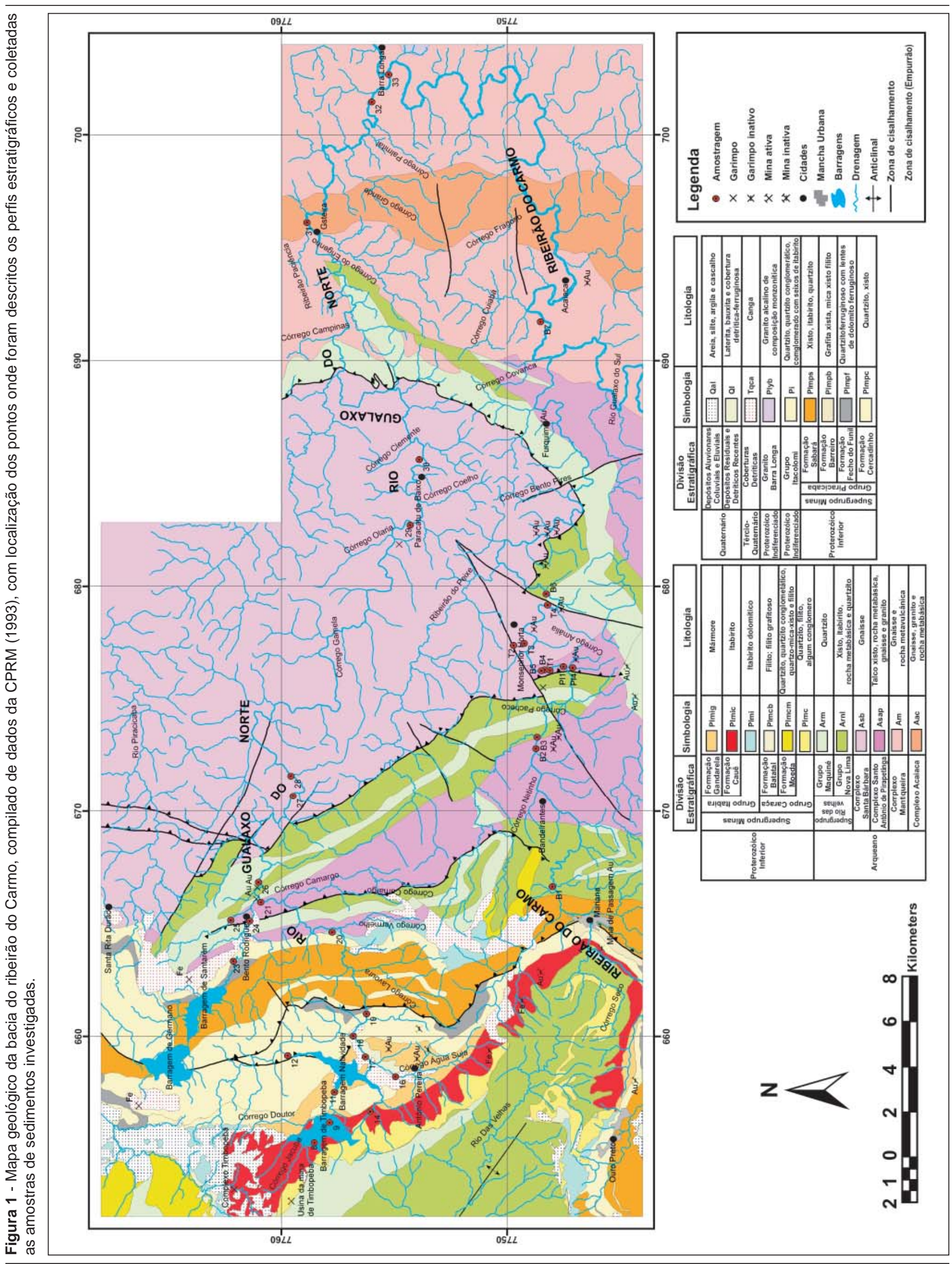

REM: R. Esc. Minas, Ouro Preto, 63(4): 703-714, out. dez. 2010705 
Análise estratigráfica e distribuição do arsênio em depósitos sedimentares quaternários da ...

com tubos de PVC até a profundidade máxima de $60 \mathrm{~cm}$ abaixo da superfície da planície de inundação, coleta de sedimentos em sete perfis verticais nos cortes do canal em ambientes de planície de inundação (cutbanks B1, B2, B3, B4, B5, B6 e B7), coleta de sedimentos em quatro perfis verticais nas paredes de terraços aluviais (T1, T2, T3 e T4) e coleta de sedimentos de fundo do canal no rio Gualaxo do Norte (Costa, 2001).

O levantamento estratigráfico do perfil objetivou distinguir fácies seguindo critérios como estruturas sedimentares, composição granulométrica e textural, composição mineralógica e conteúdo antropogênico. Foram coletadas 124 amostras de sedimentos em 11 perfis e dois testemunhos distribuídos entre Mariana (a oeste) até Acaiaca (a leste), além de 22 amostras de sedimentos de fundo do rio Gualaxo do Norte (Costa, 2001). As amostras foram submetidas a análises granulométricas e mineralógicas. Estas últimas foram realizadas através de lupa, difratometria de raios $\mathrm{X}$ e via microscopia eletrônica de varredura com espectrômetro de energia dispersiva acoplado (MEV-EDS) nos laboratórios de difratometria de raios $\mathrm{X}$ de Microscopia e Microanálise (MicroLAB) do DEGEO/UFOP. Todas as amostras de sedimentos na fração menor que $0,063 \mathrm{~mm}$ foram parcialmente digeridas por água régia e enviadas para análise química por espectrometria de emissão atômica com plasma acoplado indutivamente (ICP-AES), marca
SPECTRO CIROS CCD no Laboratório de Geoquímica Ambiental (LGqA) do DEGEO/UFOP.

A obtenção das idades dos sedimentos, principalmente dos terraços, foi conseguida através da técnica de datação via termoluminescência e luminescência oticamente estimulada, realizada no Laboratório de Vidros e Datação da Faculdade de Tecnologia de São Paulo (FATEC). Essa técnica fornece datação de sedimentos variando de 100 anos até 1 milhão de anos. A coleta de amostras de sedimentos para análise de temoluminescência foi realizada de maneira criteriosa por meio de tubos de PVC dispostos horizontalmente sobre a superfície vertical do perfil, de forma a evitar a incidência de luz.

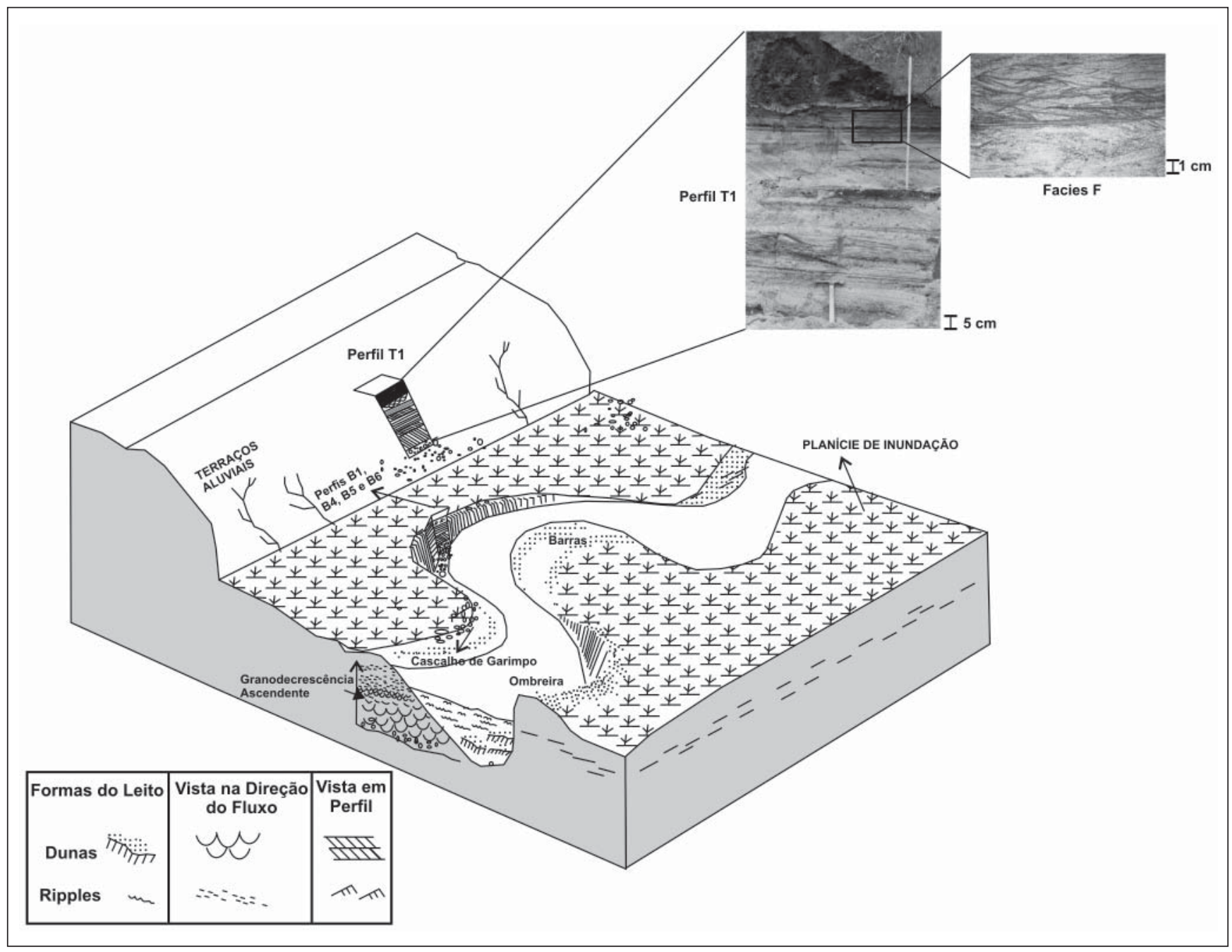

Figura 2 - Bloco-diagrama mostrando o ambiente deposicional típico de rios meandrantes e o posicionamento dos perfis onde foram coletadas as amostras de sedimentos investigadas. 
A confecção do mapa geoquímico e geológico (contendo dados compilados da CPRM, 1993) foi realizada em SIG, Sistema de Informação Geográfica, através do software ArcGis 9.0.

\section{Resultados}

A partir da descrição estratigráfica e sedimentológica, procedeu-se à análise de fácies e obteve-se a sucessão faciológica nos 7 perfis estratigráficos de cutbank, nos 2 perfis de testemunhos de planícies de inundação e nos 4 perfis de terraços aluviais (Tabela 1 e Figura 3).

A seguir será apresentada a descrição estratigráfica daqueles perfis que apresentaram fácies sedimentares correlacionadas com elevadas concentrações de As (perfil B1, B3, B5, B6 e T1). A Tabela 2 mostra a concentração de As nos depósitos sedimentares investigados.

A sucessão faciológica descrita no perfil de cutbank B1 (Figura 3 A), localizado em Mariana (Figura 1), é constituída pelas fácies $\mathbf{A}, \mathbf{B}, \mathbf{C t}$ e $\mathbf{D}$. As fácies $\mathbf{A}$ e $\mathbf{D}$ são interpretadas como depositadas em ambiente de barras de rios. A fácies $\mathbf{C t}$ originou-se por meio da deposição acumulada pela atividade garimpeira. Considerando que a draga de alcatruzes da empresa Ouro Preto Gold Mines of Brazil Limited operou no local na década de 80 , lavando os aluviões, é possível que as fácies $\mathbf{C t}$ e $\mathbf{B}$, desse perfil, tenham influência dessa atividade.

A sucessão faciológica do perfil de cutbank B3 (Figura 3 C), ocorrência em Bandeirantes (Figura 1), é constituída, da base para o topo, pelas fácies $\mathbf{U}$, D e G. Essa sucessão de fácies é uma típica deposição em ambiente de canal abandonado repentinamente (neck off). A fácies $\mathrm{G}$, rica em matéria orgânica, confirma essa hipótese.

O perfil de cutbank B5 (Figura 3 E), posicionado na região de Monsenhor Horta (Figura 1), apresenta uma sucessão de granodecrescência ascendente até $1,07 \mathrm{~m}$, tendo início com uma fácies Mt $(0,8 \mathrm{~m})$, interpretada como fácies de canal, seguida pelas fácies At, $\mathbf{F}, \mathbf{C t}$ e G. O excelente selecionamento de grãos grossos e a pouca matriz nas fácies Mt e At não são esperados a partir de processos naturais em sistemas fluviais. É provável que tenha havido um préselecionamento a montante da área de deposição pela atividade garimpeira. A fácies Ct confirma a influência antrópica no local. Nesse caso, interpreta-se o selecionamento apresentado pelos sedimentos desse estrato de cascalhos como sendo gerado pela draga que trabalhou no local há cerca de 20 anos, causando entulhamento do canal com acumulação de depósitos de cascalhos estéreis. A fácies $\mathrm{G}$ é considerada como deposição dos sedimentos em suspensão após cessar o evento de inundação, que possivelmente contribuiu para a reorganização da fácies $\mathbf{C t}$.

O perfil de cutbank B6 localizase a jusante do distrito de Monsenhor Horta (Figura 1). A sucessão faciológica do perfil B6 (Figura $3 \mathrm{~F}$ ) é constituída pelas fácies $\mathbf{A}, \mathbf{C}, \mathbf{F}$ e $\mathbf{G}$. As fácies $\mathbf{C t}$ e A caracterizam depósito de canal, sendo a fácies A depositada em barras sob regime de fluxo superior. A fácies $\mathbf{F}$ caracteriza condições de baixa energia, provavelmente associadas à porção de topo da barra. Capeando esses sedimentos, depositados em ambiente de barras, encontra-se a fácies $\mathbf{G}$, caracterizada por um espesso estrato de sedimentos argilosos depositados em ambiente de planície de inundação.

O perfil do terraço T1 (Figura 3G) localiza-se na região de Monsenhor Horta (Figura 1). O terraço $\mathrm{T} 1$ possui $2,20 \mathrm{~m}$ de altura em relação ao nível da planície de inundação do ribeirão do Carmo. Da base para o topo, o perfil apresenta uma sucessão de fácies de granodecrescência ascendente. As fácies presentes são $\mathbf{M}$, $\mathbf{A}, \mathbf{F}, \mathbf{B}, \mathbf{D}$ e $\mathbf{G}$, sendo que as 5 primeiras são essencialmente arenosas. A partir de $1,48 \mathrm{~m}$, observam-se fácies formadas por um conjunto de estratos alternados de argila avermelhada (fácies $G$ ) e areia fina de cor bege-alaranjada (fácies D). Observa-se a ocorrência do mineral dra- vita em todo o perfil, indicando provável área-fonte associada ao minério aurífero. No entanto, evidências indicam que esses sedimentos foram depositados antes do ciclo do ouro. A idade desse terraço obtida pela técnica de luminescência oticamente estimulada foi de $2.200 \pm$ 200 anos atrás.

$\mathrm{O}$ terraço $\mathrm{T} 1$ apresenta uma sucessão de granodecrescência ascendente característica de barras em pontal de rios meandrantes, sendo caracterizada na base pela fácies $\mathbf{M}$ com estratificação cruzada de grande porte produzida por mega-ripples e seixos, caracterizando depósito de canal. A fácies A com laminação horizontal é gerada em regime de fluxo superior. A fácies $\mathbf{B}$, constituída de cascalho, representa um regime de fluxo de maior energia, capaz de transportar e depositar estratos finos de cascalhos nas barras. A fácies $\mathbf{F}$, contendo laminação cruzada por ripples, representa condições de baixa energia, localizando-se próxima ao topo da barra. Essa sequência é capeada por sedimentos finos (fácies $\mathbf{G}$ e D) depositados como sedimentos em suspensão em planície de inundação.

A partir do estudo de associação de fácies, foram classificados os sistemas deposicionais dos ambientes aluviais investigados, seguindo a classificação hierárquica de Allen (1965) (in Selley 1988). Assim, foram definidas as fácies associadas aos depósitos de canal e planícies de inundação, de acordo com a Figura 4.

Com relação ao perfil de cutbank B1, observam-se concentrações de As $(765 \mathrm{mg} / \mathrm{kg}$ ) relativamente mais elevadas na fácies Ct (constituídas de areia grossa e cascalhos) e mais baixas nas fácies A e D. As anomalias de As nas fácies $\mathbf{B}$ e Ct parecem refletir a influência dos garimpos, que retiraram o ouro e concentraram este elemento nos aluviões, ligados a pequenos cristais de sulfetos como arsenopirita e calcopirita ou adsorvidos em minerais como a goethita. Essas anomalias podem ainda estar associados a argilominerais presentes nas fraturas dos grãos maiores de dravita e hematita. 
Análise estratigráfica e distribuição do arsênio em depósitos sedimentares quaternários da ...

Tabela 1 - Nomenclatura das fácies sedimentares e a interpretação dos possíveis ambientes de deposição.

\begin{tabular}{|c|c|c|c|c|c|}
\hline Fácies & $\begin{array}{l}\text { Granulometria } \\
\text { predominante }\end{array}$ & Minerais predominantes & $\begin{array}{c}\text { Estruturas } \\
\text { sedimentares }\end{array}$ & $\begin{array}{l}\text { Evidências de } \\
\text { depósitos } \\
\text { tecnogênicos }\end{array}$ & Ambiente de Deposição \\
\hline A & $\begin{array}{l}\text { Areia fina a } \\
\text { média }\end{array}$ & $\begin{array}{l}\text { Quartzo, caulinita, } \\
\text { moscovita, hematita e } \\
\text { cianita }\end{array}$ & $\begin{array}{l}\text { Estratificação } \\
\text { plano-paralela }\end{array}$ & Ausente & Barras em pontal \\
\hline B & $\begin{array}{l}\text { Areia grossa e } \\
\text { cascalhos }\end{array}$ & $\begin{array}{l}\text { Quartzo, hematita, } \\
\text { moscovita, caulinita, } \\
\text { sulfetos e dravita }\end{array}$ & Ausente & Ausente & $\begin{array}{l}\text { Diques de cascalho } \\
\text { (atividade garimpeira) ou } \\
\text { em barras }\end{array}$ \\
\hline $\mathrm{Ct}$ & $\begin{array}{l}\text { Cascalhos com } \\
\text { matacões }\end{array}$ & $\begin{array}{c}\text { Quartzo, hematita, } \\
\text { magnetita, moscovita, } \\
\text { goethita, sulfetos e dravita }\end{array}$ & Ausente & $\begin{array}{l}\text { Pouca matriz e } \\
\text { objetos de ferro } \\
\text { e plásticos }\end{array}$ & $\begin{array}{c}\text { Canal com interferência } \\
\text { direta de garimpo ou } \\
\text { draga }\end{array}$ \\
\hline D & $\begin{array}{l}\text { Areia fina a } \\
\text { média }\end{array}$ & $\begin{array}{c}\text { Quartzo, hematita, sulfetos, } \\
\text { moscovita, caulinita }\end{array}$ & Ausente & ausente & $\begin{array}{l}\text { Barras com baixa } \\
\text { velocidade de fluxo }\end{array}$ \\
\hline At & $\begin{array}{l}\text { Areia grossa } \\
\text { com seixos }\end{array}$ & $\begin{array}{c}\text { Quartzo, hematita, } \\
\text { magnetita, sulfetos, dravita } \\
\text { e goethita }\end{array}$ & $\begin{array}{l}\text { Estratificação } \\
\text { plano-paralela }\end{array}$ & Pouca matriz & $\begin{array}{c}\text { Barras com interferências } \\
\text { antropogênicas. Em regime } \\
\text { de fluxo superior }\end{array}$ \\
\hline $\mathbf{F}$ & $\begin{array}{l}\text { Areia fina a } \\
\text { média }\end{array}$ & $\begin{array}{c}\text { Quartzo, hematita, goethita } \\
\text { e cianita }\end{array}$ & $\begin{array}{l}\text { Laminação } \\
\text { cruzada por } \\
\text { ripples }\end{array}$ & Ausente & $\begin{array}{c}\text { Topo de barras, depósitos } \\
\text { de levee /baixa energia }\end{array}$ \\
\hline G & Argila & $\begin{array}{c}\text { Quartzo, hematita, } \\
\text { moscovita, illita, goethita, } \\
\text { cianita, caulinita e } \\
\text { interestratificado de } \\
\text { illita/esmectita }\end{array}$ & $\begin{array}{l}\text { Estratificação } \\
\text { plano-paralela }\end{array}$ & Ausente & $\begin{array}{c}\text { Lagoa de cheia ou planície } \\
\text { de inundação }\end{array}$ \\
\hline Mt & $\begin{array}{l}\text { Areia grossa e } \\
\text { muito grossa }\end{array}$ & $\begin{array}{c}\text { Quartzo, hematita, } \\
\text { magnetita, sulfetos, dravita } \\
\text { e goethita }\end{array}$ & $\begin{array}{l}\text { Estratificações } \\
\text { cruzadas } \\
\text { centimétricas }\end{array}$ & Pouca matriz & $\begin{array}{l}\text { Canal com interferências } \\
\text { antropogênicas indiretas }\end{array}$ \\
\hline M & $\begin{array}{l}\text { Areia grossa e } \\
\text { muito grossa }\end{array}$ & $\begin{array}{l}\text { Quartzo, hematita, } \\
\text { magnetita goethita e } \\
\text { dravita }\end{array}$ & $\begin{array}{l}\text { Estratificações } \\
\text { cruzadas } \\
\text { centimétricas }\end{array}$ & Ausente & Canal \\
\hline $\mathbf{L}$ & $\begin{array}{l}\text { Silte e argila e } \\
\text { areia fina (T4) }\end{array}$ & $\begin{array}{l}\text { Quartzo, moscovita, } \\
\text { caulinita e gibbsita }\end{array}$ & $\begin{array}{c}\text { Algumas vezes } \\
\text { estratificações } \\
\text { plano-paralelas }\end{array}$ & Ausente & $\begin{array}{l}\text { Planície de inundação ou } \\
\text { lagoa de cheia }\end{array}$ \\
\hline $\mathbf{U}$ & Cascalho & $\begin{array}{l}\text { Quartzo, talco, mica, } \\
\text { zinnwaldita e clinocloro }\end{array}$ & Ausente & Ausente & Canal \\
\hline $\mathbf{S}$ & $\begin{array}{l}\text { Cascalho e } \\
\text { areia grossa }\end{array}$ & $\begin{array}{c}\text { Quartzo, gibbsita, caulinita } \\
\text { e moscovita }\end{array}$ & Ausente & Ausente & Fluxo de detritos \\
\hline
\end{tabular}


Adivane Terezinha Costa et al.

No perfil de cutbank B3, foram observadas concentrações elevadas de As $(390,10 \mathrm{mg} / \mathrm{kg})$ na fácies $\mathbf{G}$, associadas principalmente a um incremento na quantidade de matéria orgânica complexada com argilominerais presentes.
Com relação ao perfil B5, observase que, da base para o topo, ocorre uma diminuição das concentrações de As, que apresenta valores máximos de 475,20 $\mathrm{mg} / \mathrm{kg}$ na fácies Mt.
$\mathrm{Na}$ assinatura geoquímica do As do perfil de cutbank B6, podem ser observados dois padrões geoquímicos distintos. O primeiro está associado às fácies enriquecidas em óxidos de ferro (fácies $\mathbf{A}, \mathbf{C t}$ e F), que mostram enrique-

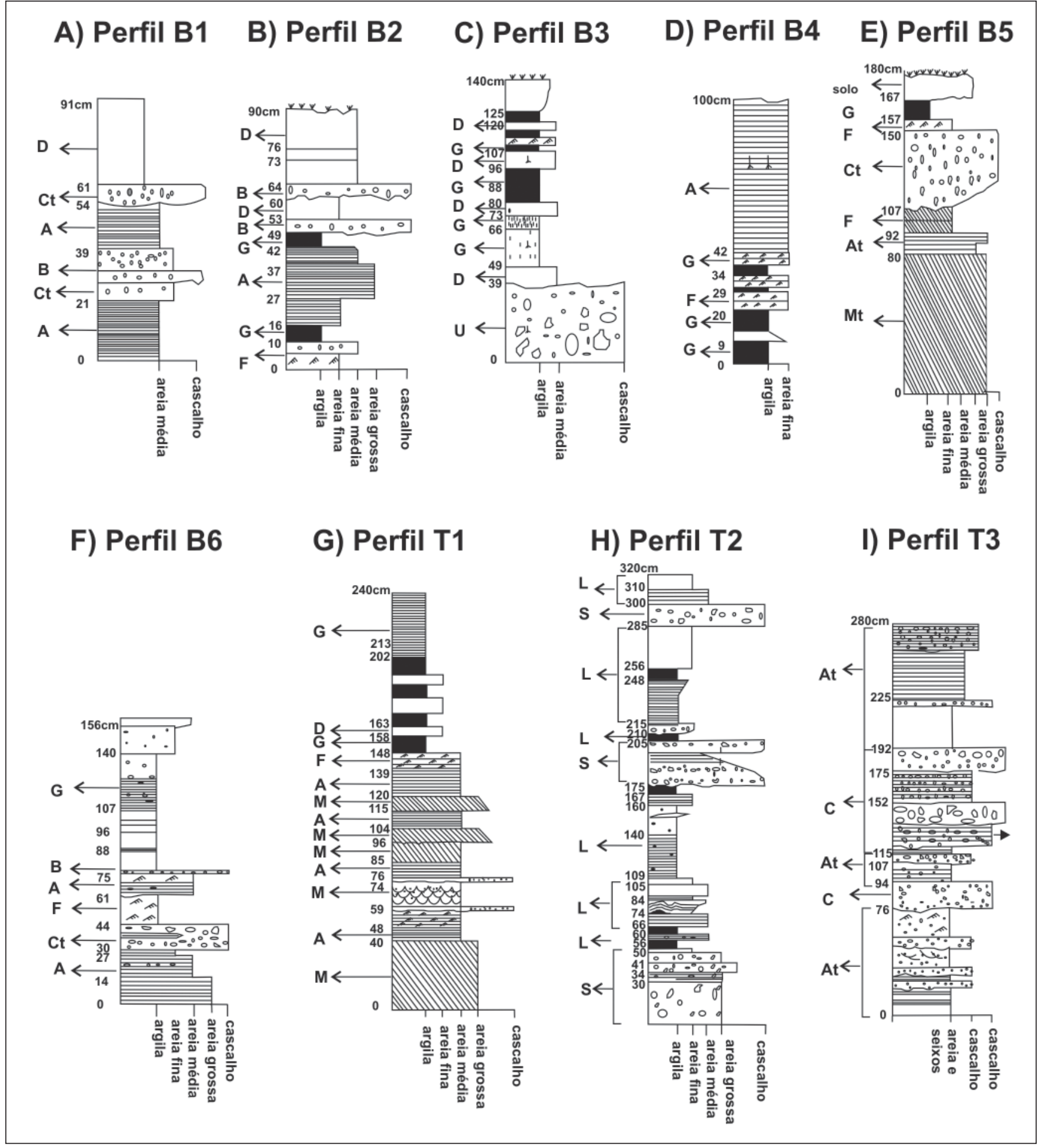

Figura 3 - Perfis estratigráficos dos perfis de cutbank B1, B2, B3, B5, B6 e terraços T1, T2 e T3. 


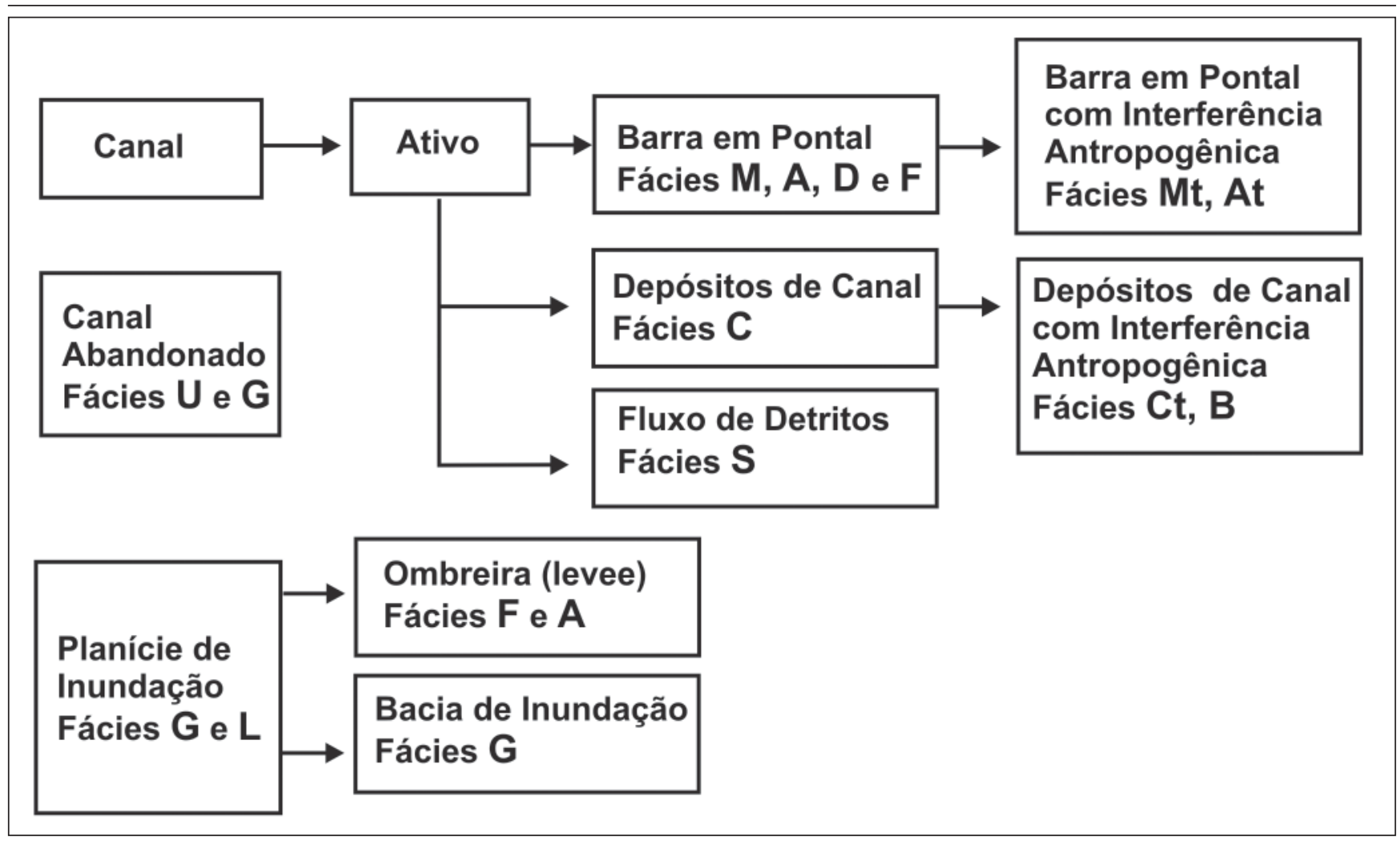

Figura 4 - Classificação dos ambientes aluviais observados nesse trabalho a partir do estudo de associação de fácies, modificado da classificação hierárquica de Allen (1965, in Selley, 1988).

cimento em As. A fácies Ct apresentou concentração anômala de As $(2871 \mathrm{mg} /$ $\mathrm{kg}$ ). Nesse primeiro caso, as anomalias de As provavelmente são provenientes de sulfetos como arsenopirita e de goethita com traços As adsorvido. Essa anomalia de As sugere contaminação proveniente de interferência antrópica indireta, associada aos rejeitos enriquecidos em As provenientes das minas de ouro principalmente de Passagem de Mariana, que eram lançados diretamente no ribeirão do Carmo desde o final do século XVII. Esses rejeitos foram concentrados em ambiente de canal, muitas vezes em sedimentos de granulometria grossa.

O segundo padrão está associado à fácies $\mathbf{G}$, onde se encontra grande quantidade de sedimentos finos ricos em caulinita e gibbsita, apresentando baixas concentrações de As. A rocha fonte deve ser enriquecida em feldspatos, possivelmente associada às rochas gnáissicas do Complexo Metamórfico Santa Bárbara, enquanto que as fácies inferiores $\mathbf{A}, \mathbf{F}$ e $\mathbf{B}$ enriquecidas em óxidos de ferro e sulfetos estão associadas a rochas supracrustais (Supergrupos Rio das Velhas e Minas).

Com relação à assinatura geoquímica do As no perfil de terraço T1, observam-se concentrações elevadas em praticamente todo o perfil. Nos sedimentos arenosos depositados em barras em pontal, as concentrações elevadas de arsênio parecem estar relacionadas à presença de minerais pesados como arsenopirita e goethita com As adsorvido, como foi observado em análises de microscopia eletrônica de varredura com espectrômetro de energia dispersiva acoplado (MEV-EDS). Anômalas são as concentrações desse elemento nas fácies $\mathbf{F}(1476 \mathrm{mg} / \mathrm{kg})$ e $\mathbf{G}(1326$ $\mathrm{mg} / \mathrm{kg}$ ), associadas a sedimentos finos, principalmente adsorvido nas argilas depositadas em ambiente de planície de inundação. Neste caso, o As encontra-se adsorvido em estruturas de goethita e de argilominerais como illita e interestratificado de illita-esmectita.
O mineral dravita, identificado por MEV-EDS, encontrado no terraço T1, indica que as anomalias na concentração de As desse terraço devem estar associadas às fontes geogênicas com alto teor em ouro associado a turmalinitos, que ocorrem principalmente em Passagem de Mariana. A idade desses sedimentos (2.200 \pm 200 anos atrás) indica que esses sedimentos ricos em As foram depositados antes da implantação da mineração na região.

\section{Discussão dos resultados}

A análise do valor de referência para o arsênio (Figura 5) foi realizada com base na confecção de curvas de freqüência acumulada em escala linear (Matschullat et al. 2000) para sedimentos que foram depositados em ambiente de canal (Figura 5a) e para sedimentos depositados em planícies de inundação (Figura 5b). Em sedimentos depositados 
Adivane Terezinha Costa et al.

Tabela 2 - Concentração de As nas fácies dos perfis investigados.

\begin{tabular}{|c|c|c|c|c|c|c|c|c|c|c|c|c|c|c|}
\hline Pontos & B1 A & B1 B & B1 A & $\mathrm{B} 1 \mathrm{Ct}$ & B1 D & B2 F & B2 G & B2 A & B2 A & B2 A & B2 G & B2 B & B2 D & B2 B \\
\hline altura $(\mathrm{cm})$ & $0-21$ & 21-39 & $39-54$ & $54-61$ & $61-91$ & $0-10$ & $10-16$ & $16-27$ & $27-37$ & $37-42$ & $43-49$ & $49-53$ & $53-60$ & $60-64$ \\
\hline $\mathrm{As}(\mathrm{mg} / \mathrm{kg})$ & 383,6 & 649 & 469,9 & 700 & 144,4 & 312 & 379,1 & 401,8 & 214,2 & 177,3 & 8,72 & 435,2 & 1,01 & 390 \\
\hline Pontos & B3 U & B3 D & B3 L & B3 G & B3 D & B3 G & B3 G & B3 D & B3 D & B3 G & B3 solo & PI1 & PI1 & PI1 \\
\hline altura $(\mathrm{cm})$ & $0-39$ & $39-49$ & $49-66$ & $66-73$ & $73-80$ & $80-88$ & $88-96$ & 96-107 & $107-120$ & $120-125$ & $125-140$ & $0-12$ & $12-33$ & $33-42$ \\
\hline $\mathrm{As}(\mathrm{mg} / \mathrm{kg})$ & 20,19 & 9,28 & 80,9 & 390,10 & 418,1 & 198,6 & 176,3 & 123,9 & 83,9 & 155,1 & 232,3 & 299,2 & 293,8 & 229,5 \\
\hline Pontos & PI1 & PI4 & PI4 & $\mathrm{PI} 4$ & $\mathrm{PI} 4$ & PI4 & PI4 & $\mathrm{PI} 4$ & PI4 & $\mathrm{Pl} 4$ & PI4 & PI4 & & PI4 \\
\hline Prof. (cm) & $48-57$ & $0-12$ & $12-19$ & $19-21$ & $21-27$ & $27-37$ & $37-52$ & FS2 & FS3 & FS4 & FS5 & FS6 & FS7 & FS8 \\
\hline $\mathrm{As}(\mathrm{mg} / \mathrm{kg})$ & 157,2 & 145,7 & 211,3 & 241,4 & 191,5 & 131 & 272,7 & 160,9 & 140,8 & 143,4 & 126,2 & 133,7 & 134,8 & 151,3 \\
\hline Pontos & B4 G & B4 F & B4 G & B4 F & B4 G & B4 A & B5 Mt & B5 At & B5 At & B5 F & B5 Ct & B5 F & B5 G & B5 solo \\
\hline altura $(\mathrm{cm})$ & $12-20$ & $20-27$ & $27-29$ & $29-34$ & $37-42$ & $42-100$ & $0-80$ & $80-83$ & 83-92 & 92-107 & $107-150$ & 150-157 & 157-167 & 167-180 \\
\hline $\mathrm{As}(\mathrm{mg} / \mathrm{kg})$ & 130,2 & 99 & 54,4 & 72,9 & 35,31 & 66,7 & 475,2 & 387,6 & 229,3 & 226,3 & 194,1 & 0,73 & 88,7 & 139,7 \\
\hline Pontos & B6 A & B6 B & B6 F & B6 A & B6 L & B6 L & B6 L & B6 solo & B7 D & B7 D & B7 F & B7 M & B7 F & B7 M \\
\hline altura $(\mathrm{cm})$ & $0-27$ & $30-44$ & $44-61$ & $61-75$ & $75-88$ & $88-96$ & 107-140 & $140-156$ & $0-28$ & $50-70$ & $70-94$ & 94-104 & 104-117 & 117-161 \\
\hline $\mathrm{As}(\mathrm{mg} / \mathrm{kg})$ & 660 & 2691 & 631 & 503 & 10 & 3,85 & 4,18 & 3,04 & 371,3 & 594 & 107,4 & 191,9 & 93,5 & 705 \\
\hline Pontos & B7 F & T1 M & T1 A & T1 F & T1 M & T1 B & T1 A & T1 M & $\mathrm{T} 1 \mathrm{M}$ & T1 A & $\mathrm{T} 1 \mathrm{M}$ & T1 A & T1 F & T1 G \\
\hline altura $(\mathrm{cm})$ & $207-249$ & $0-40$ & $40-48$ & $48-59$ & $59-74$ & $74-76$ & $76-85$ & $85-96$ & 96-104 & 104-115 & $115-120$ & $120-139$ & 139-148 & 148-158 \\
\hline $\mathrm{As}(\mathrm{mg} / \mathrm{kg})$ & 118,4 & 630 & 529 & - & 605 & 457,9 & 572 & 450,7 & 433,3 & 507 & 695 & 669 & 1476 & 1326 \\
\hline Pontos & T1 G & T1 G & T2 S & T2 S & $\mathrm{T} 2 \mathrm{~S}$ & T2 S & T2 L & T2 L & T2 L & T2 L & $\mathrm{T} 2 \mathrm{~L}$ & $\mathrm{~T} 2 \mathrm{~L}$ & $\mathrm{~T} 2 \mathrm{~L}$ & T2 L \\
\hline altura $(\mathrm{cm})$ & 202-213 & $213-240$ & $0-28$ & 30-34 & $34-41$ & $41-48$ & $50-56$ & $60-66$ & $69-74$ & $74-84$ & $87-105$ & 105-109 & 109-140 & $140-160$ \\
\hline $\mathrm{As}(\mathrm{mg} / \mathrm{kg})$ & 710 & 1047 & 0,73 & 0,73 & 10,21 & 0,73 & 0,73 & 0,76 & 0,65 & 0,73 & 0,73 & 0,7 & 0,73 & 0,73 \\
\hline Pontos & T2 L & T2 S & T2 L & $\mathrm{T} 2 \mathrm{~L}$ & T2 L & T2 S & T2 solo & T3 At & T3 Ct & T3 At & T3 At & $\mathrm{T} 3 \mathrm{Ct}$ & T3 D & T4 L \\
\hline altura $(\mathrm{cm})$ & $167-175$ & $175-202$ & $205-210$ & $210-248$ & $248-256$ & \begin{tabular}{|l|}
$285-300$ \\
\end{tabular} & $310-320$ & $0-76$ & 76-94 & 94-107 & $107-115$ & 115-192 & $192-225$ & $0-60$ \\
\hline $\mathrm{As}(\mathrm{mg} / \mathrm{kg})$ & 0,65 & 0,8 & 0,73 & 0,73 & 0,7 & 0,73 & 0,7 & 262,6 & 318,6 & 229,5 & 215,7 & 169,6 & 274,1 & 2,98 \\
\hline
\end{tabular}

a)

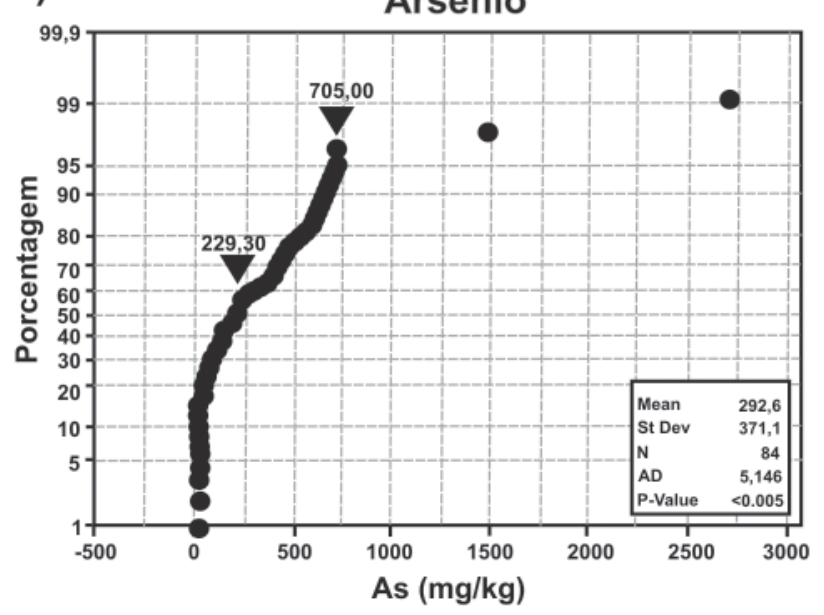

b)

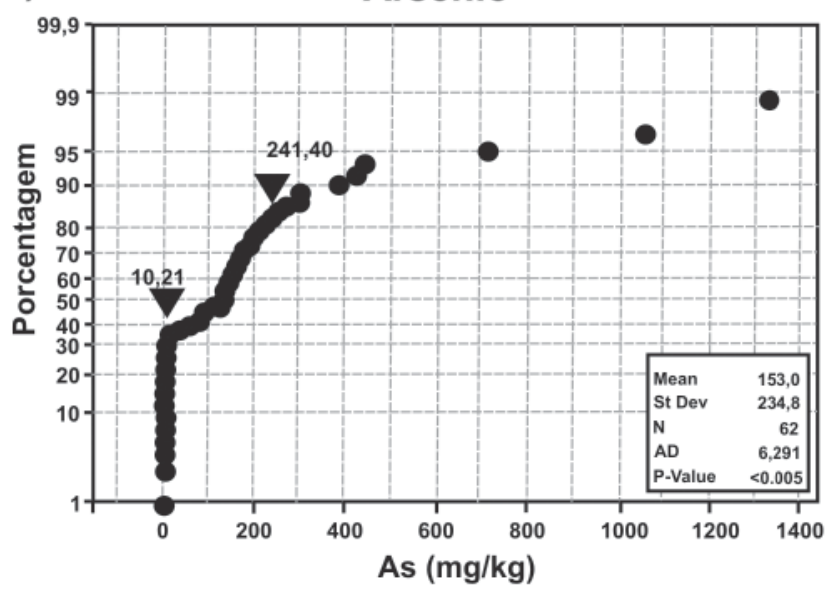

Figura 5 - Diagrama de freqüência acumulada para sedimentos depositados em: a) fácies de canal e b) fácies de planícies de inundação. 
Análise estratigráfica e distribuição do arsênio em depósitos sedimentares quaternários da ...

em canal, foram incorporados dados de sedimentos de fundo de Costa (2001).

Os diagramas de frequência acumulada do As de sedimentos de canal apresentaram, pelo menos, duas populações bem definidas (Figura 5), tendo sido determinados os valores de referência: $229 \mathrm{mg} / \mathrm{kg}$ e $700 \mathrm{mg} / \mathrm{kg}$. Os sedimentos de planícies de inundação apresentaram valores de referência mais baixos: 10,21 $\mathrm{mg} / \mathrm{kg}$ e $241,40 \mathrm{mg} / \mathrm{kg}$.

Vale ressaltar que os dois valores de referência obtidos para o As parecem refletir duas populações de valor de referência, em que a primeira está associada às rochas gnáissicas dos complexos metamórficos e a segunda, às rochas supracrustais com pouca interferência antropogênica.
Para uma análise espacial dos valores obtidos das concentrações de As em fácies sedimentares de planícies de inundação e de terraços aluviais do ribeirão do Carmo, elaborou-se um mapa geoquímico georeferenciado baseado no valor de referência (Figura 6).

As cores dos círculos referentes aos intervalos de valores da concentração geoquímica dos elementos-traço do mapa geoquímico representam intervalos limitados pelo valor de referência obtido pelo método estatístico. Assim, os círculos de coloração verde representam os intervalos de valores abaixo do valor de referência natural, apresentando baixo risco ambiental para o ecossistema local. Os círculos de coloração laranja representam os intervalos de valores que se situam entre duas populações que podem estar associados a fontes naturais ou antropogênicas. Os círculos de coloração vermelha representam áreas com concentrações anômalas de arsênio em sedimentos e estão associadas principalmente à interferência antropogênica direta ou indireta, caracterizando-se como áreas de elevado risco ambiental.

Em sedimentos de fácies de canal do ribeirão do Carmo, observam-se concentrações elevadas e anômalas de As, bem acima do valor de referência, em todo o segmento investigado da bacia, com exceção dos perfis B3, B4 e T2 (Figura 6).

Em sedimentos de fácies de canal foram observadas concentrações anômalas de arsênio para os sedimentos do perfil B1 (área 1 - Mariana), que ocorrem mais próximos das principais áreasfonte de As (sulfetos de Passagem de

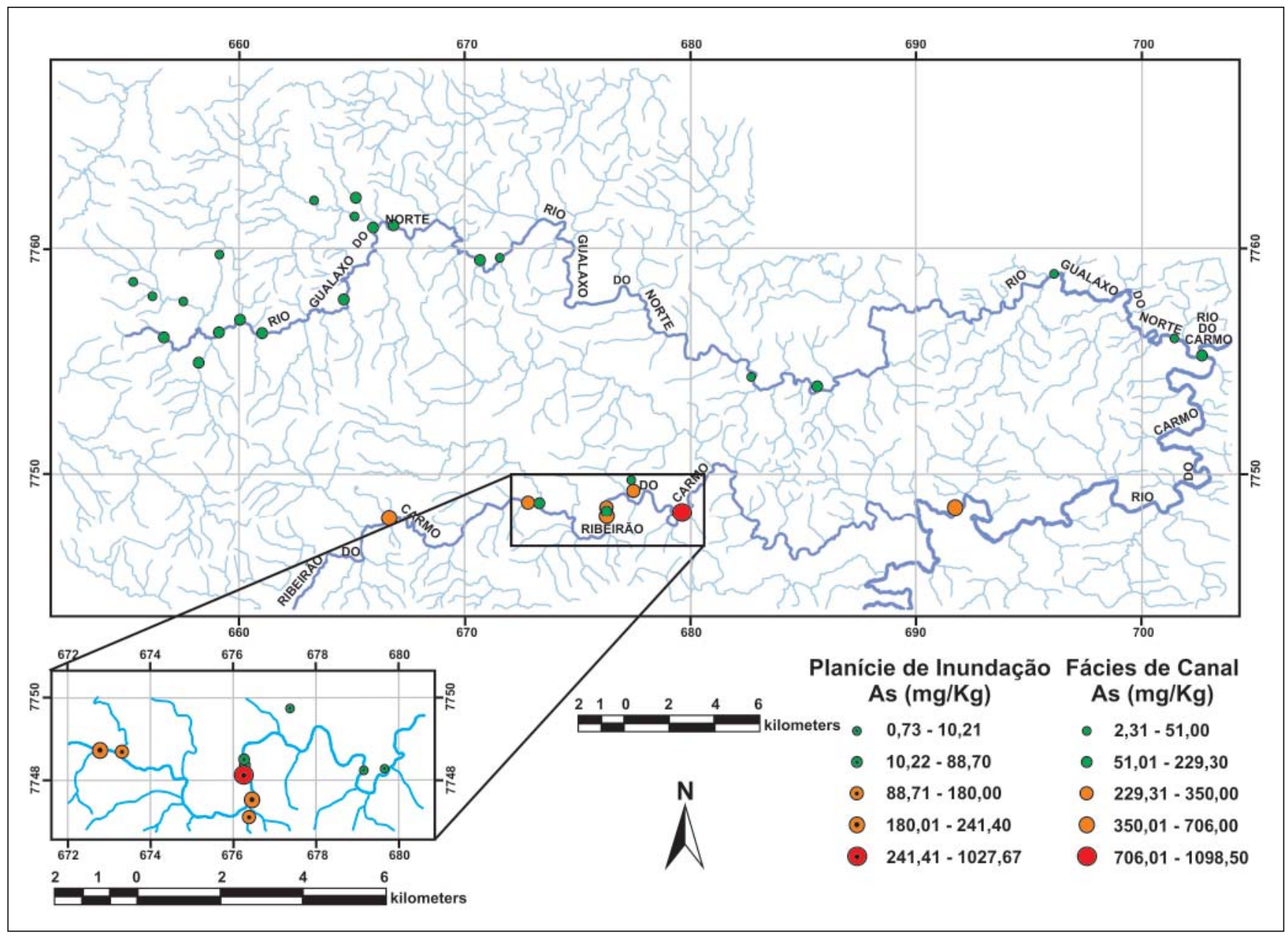

Figura 6 - Mapa geoquímico do arsênio para fácies de canal e planície de inundação do ribeirão do Carmo e do rio Gualaxo do Norte. 
Mariana), apresentando concentrações médias variando entre 350 a $706 \mathrm{mg} / \mathrm{kg}$, assim como o perfil PI1 (localizado na região de Monsenhor Horta) e o perfil B7 (localizado no município de Acaiaca). Concentrações também bastante anômalas de As (média variando de 706 - 1098 $\mathrm{mg} / \mathrm{kg}$ ) foram observadas em estratos inferiores do perfil de cutbank B6, em Monsenhor Horta.

O mapa geoquímico de sedimentos de planície de inundação engloba somente as áreas Bandeirantes e Monsenhor Horta (Figura 6). O elevado volume de fácies argilosas, nessa área, reflete o desenvolvimento de uma potente área de deposição sedimentar caracterizada por um sistema fluvial meandrante bem desenvolvido.

Em sedimentos de fácies de planície de inundação (Figura 6), observamse concentrações anômalas de As em sedimentos do terraço T1 (média variando de 241,4 -1027,7 mg/kg). Como se trata de um terraço depositado antes do ciclo do ouro (2200 \pm 300 anos, holoceno - neógeno superior) e como apresenta enriquecimento no mineral dravita, a rocha-fonte desses sedimentos ricos em As está certamente associada à mineralização de ouro encaixada em turmalinitos, que ocorre principalmente em Passagem de Mariana, cujo processo de erosão, transporte e deposição ocorreu antes do ciclo do ouro. O enriquecimento em As é também favorecido pelo ambiente de deposição, tipicamente associado a rios meandrantes.

\section{Conclusão}

A presença de fácies de barra em pontal com estruturas sedimentares características, fácies de planícies de inundação bem desenvolvidas e a granodecrescência ascendente dos perfis B3, B4, B6 e T1 confirmam o padrão dos depósitos sedimentares gerados em sistema fluvial meandrante. O processo de agradação, influenciado pela atividade de exploração aurífera secular, pode ser claramente observado através das características sedimentológicas nos perfis B1, B5 e T3.
Os depósitos de canal e barra em pontal caracterizam-se como locais onde predomina a concentração de minerais pesados, como dravita, arsenopirita, entre outros. Esse ambiente deposicional é também o local de enriquecimento de ouro e, portanto, de maior contaminação por As.

Estudos geoquímicos realizados em planícies de inundação mostram que ambientes deposicionais caracterizados pela presença de sedimentos finos são comumente associados com altas concentrações de metais-traço (Wolfenden \& Lewin, 1978, Ansari et al., 2001). No ribeirão do Carmo, as partículas mais finas na fração argila também estão associadas com elevadas concentrações de As e são transportadas em suspensão pelas águas fluviais, vindo a se depositar nas planícies de inundação.

Os sedimentos das planícies de inundação podem registrar, então, variação na contaminação ao longo de um determinado período de tempo, portanto guardando a "memória" da poluição dos sedimentos de um determinado rio (Miller, 1997). Diante das investigações realizadas, é possível admitir que, no ambiente secundário, o arsênio provavelmente é capturado por óxidos e hidróxidos de ferro e argilo-minerais através de fenômenos de adsorção no ambiente superficial, após a oxidação dos sulfetos.

Foram observadas concentrações relativamente mais elevadas de As em sedimentos da bacia do ribeirão do Carmo, quando comparadas com a bacia do rio Gualaxo do Norte (Costa, 2001), como observado no mapa da Figura 6, sendo reflexo da maior potencialidade das jazidas auríferas e, conseqüentemente, da exploração aurífera secular nas áreas da mina de Passagem e região de Ouro Preto. A disponibilidade acelerada de potentes quantidades dos metais como As, presente em rochas, águas, solos e sedimentos, ocorre a partir de áreas mineradas ou garimpadas. Os rejeitos enriquecidos em sulfetos de As (arsenopirita), no alto curso do ribeirão do Carmo, foram disponibilizados por áreas-fontes associadas à mineralização aurífera e enriquecidos em áreas de deposição a jusante. Entre as áreas de deposição impactadas, destacam-se as planícies e terraços aluviais do ribeirão do Carmo, principalmente aquelas dos distritos de Bandeirantes e Monsenhor Horta, consideradas como área potencialmente degradada pela atividade de exploração histórica de ouro.

A partir do mapa, tornam-se legíveis para a comunidade científica e autoridades políticas as áreas potencialmente contaminadas. Acredita-se que, por meio dessa base de dados geoquímicos, será possível elaborar um plano político ambiental e estudos de geologia médica envolvendo análises de água de consumo. Através dessas ações, pode-se minimizar os impactos causados pelas atividades de exploração auríferas histórica, principalmente nos locais onde se instalaram as comunidades ribeirinhas.

\section{Agradecimentos}

A realização desse trabalho foi possível através do suporte financeiro dos projetos FAPEMIG (CRA952/01), CAPES_DAAD PROBAL (162/03, cooperação Brasil Alemanha). Os autores agradecem também ao laboratório de Geoquímica do DEGEO/UFOP e à CAPES pela bolsa de doutorado da primeira autora.

\section{Referências bibliográficas}

ANSARI, A.A., SINGH, I. B., TOBSCHALL, H. J. Importance of geomorphology and sedimentation processes for metal dispersion in sediments and soils of Ganga Plain: identification of geochemical domains. Chemical Geology, n.162, p. 245-226, 2001.

BORBA, R. P. Arsênio em ambiente superficial: processos geoquímicos naturais e antropogênicos em uma área de mineração aurífera. Instituto de Geociências, Universidade Estadual de Campinas, 2002. 111p. (Dissertação de Mestrado). 
Análise estratigráfica e distribuição do arsênio em depósitos sedimentares quaternários da ...

COSTA, A. T. Geoquímica das águas e sedimentos da bacia do Rio Gualaxo do Norte, leste-sudeste do Quadrilátero Ferrífero (MG): Estudo de uma área afetada por atividade de extração mineral. Ouro Preto: Departamento de Geologia, Universidade Federal de Ouro Preto, 2001. 146p. (Dissertação de Mestrado).

COSTA, A. T., NALINI Jr. H. N., CASTRO, P. T. A., LENA, J. C., MORGENSTERN, P., FRIESE, K. Sediment contamination in floodplains and aluvial terraces as na historical recordo f gold exloitation in the Carmo river basin, Southeast Quadrilátero Ferrífero, Minas Gerais, Brazil. Acta hydrochim. Hidrobiol., 34, p. 245-256, 2006.

COSTA, A. T. Registro histórico de contaminação de metais pesados associados à exploração aurífera no alto e médio curso da bacia do Ribeirão do Carmo, QF: um estudo de sedimentos de planícies de inundação e terraços aluviais. Ouro Preto: Departamento de Geologia, Universidade Federal de Ouro Preto, 2007. 255p. (Tese de Doutorado).

CPRM. Texto Explicativo - Mariana, Folha SF.23-X-B. Programa Levantamentos Geológicos Básicos do Brasil. Brasília, DNPM/ CPRM, 1993. 183p.

ELEUTÉRIO, L. Diagnóstico da situação ambiental da cabeceira da bacia do Rio Doce, MG, no âmbito das contaminações por metais pesados, em sedimentos de fundo. Ouro Preto: Departamento de Geologia, Universidade Federal de Ouro Preto, 1997. 154 p. (Dissertação de Mestrado).

ESCHWEGE, W. L. Von. Pluto Brasilienses. Belo Horizonte: Ed. Itatiaia-Edusp, 1979. v. 2.

FIGUEIREDO, B. R. Minérios e Meio Ambiente. Campinas: Ed. da Unicamp, 2000. 540p.

LADEIRA, A. C. Q. Utilização de solos e minerais para immobilização de arsênio e mecanismos de adsorção. Universidade Federal de Minas Gerais, 1999. 157p. (Tese de Doutorado).
MATSCHULLAT, J., OTTENSTEIN, R., REIMANN, C. Geochemical background - can we calculate it? Environmental Geology, v. 39, n. 9, p. 990-1000, 2000.

MILLER, J. R. The role of fluvial geomorphic processes in the dispersal of heavy metals from mine sites. Journal of Geochemical Exploration, v. 59, p. 101-118, 1997.

OLIVEIRA, M. R. Investigação por contaminação por metais pesados no sedimento de corrente e água do Parque Estadual do Itacolomi, Minas Gerais e Arredores. Ouro Preto: Departamento de Geologia, Universidade Federal de Ouro Preto, 1999. 180p. (Dissertação de Mestrado).

PEREIRA, M. A. Estudo de elementos-traço em águas de abastecimento urbano e contaminação humana: um caso de Ouro Preto, MG. DEGEO/UFOP. 2006. 76p. (Dissertação de Mestrado).

PIMENTEL, H. S. Caracterização geoquímica da contaminação das águas da serra de Ouro Preto, Minas Gerais. Universidade Federal de Ouro Preto, 2001. 113 p. (Tese de Mestrado).

SELLEY, R. C. Applied Sedimentology. London Academic. Press Limited, 1998. 446p.

VIAL, D. S. Mina de Ouro de Passagem de Mariana, Minas Gerais. In: SCHOBBENHAUS, C., COELHO, C.E.S. Principais Depósitos Minerais do Brasil. Brasília: DNPM, CVRD, 1988. p.421-430.

WHO, World Health Organization United Nations Synthesis Report on Arsenic in Drinking water, Geneva, World HealthOrganization. 2001. (http:/www.who.int/water_sanitation_health/Arsenic/ ArsenicUNReptoc.htm). Acesso em 02/05/2004

WOLFENDEN, P. J., LEWIN, J. Distribution of metal pollutants in active stream sediments. Catena, 5, p. 67-78, 1978.

Artigo recebido em 10/06/2009 e aprovado em 17/06/2010.

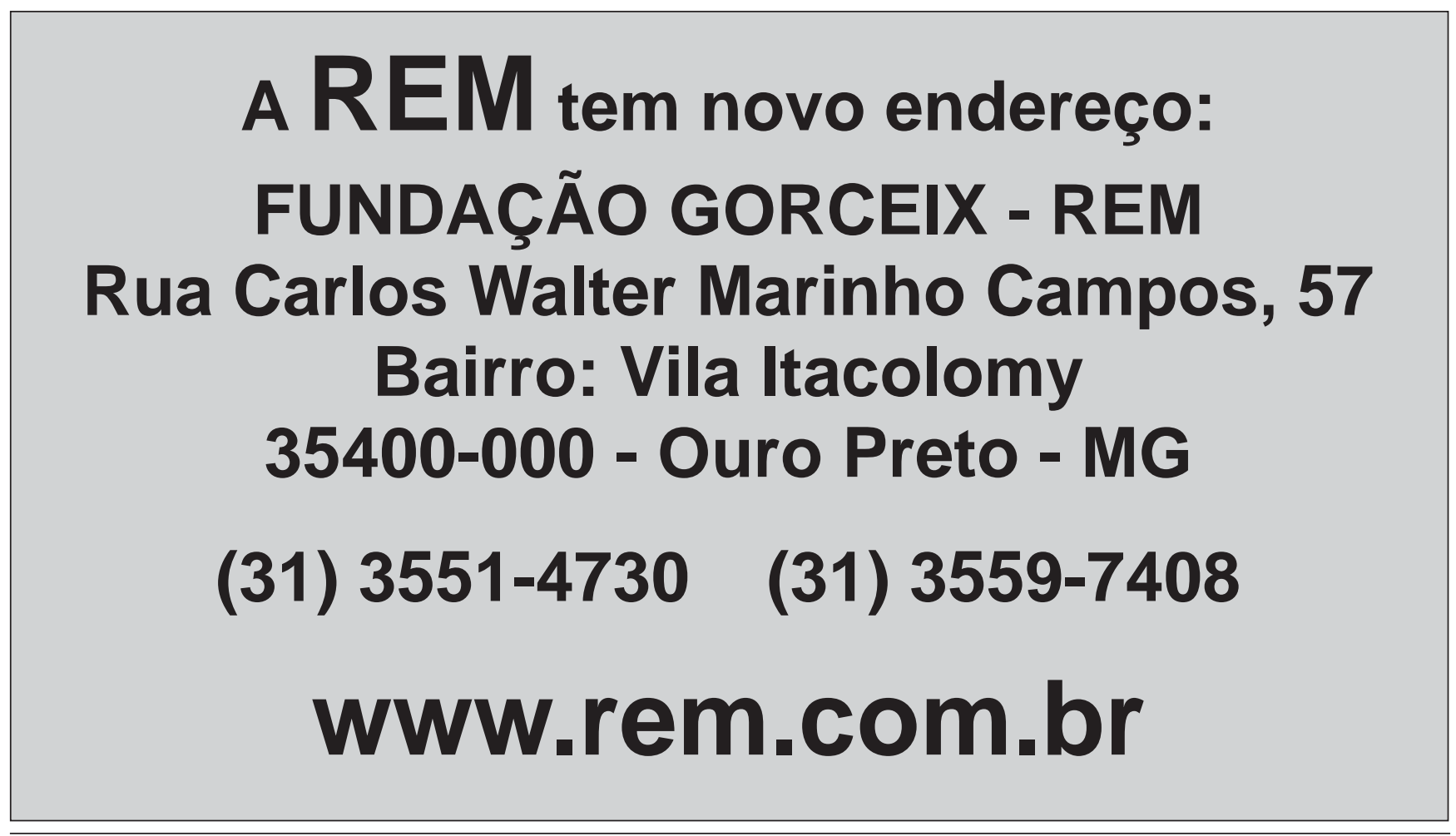

714 REM: R. Esc. Minas, Ouro Preto, 63(4): 703-714, out. dez. 2010 